\title{
LA-UR- $98-2659$
}

Approved for public release; distribution is unlimited.
Title:

Effects of Thermomechanical Processing on the Resulting Mechanical Properties of 6101 Aluminum Foam

$$
\text { CONF-980405-- }
$$

Author(s):

Robert Margevicius

Paul Stanek

Loren Jacobson

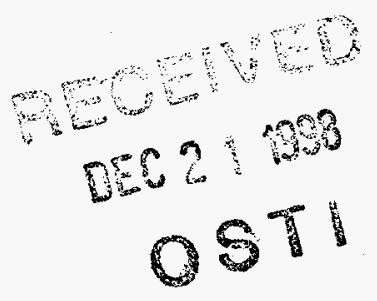

\section{Los Alamos}

\section{NATIONAL LABORATORY}

Los Alamos National Laboratory, an affirmative action/equal opportunity employer, is operated by the University of California for the U.S. Department of Energy under contract W-7405-ENG-36. By acceptance of this article, the publisher recognizes that the U.S. Government retains a nonexclusive, royalty-free license to publish or reproduce the published form of this contribution, or to allow others to do so, for U.S. Government purposes. Los Alamos National Laboratory requests that the publisher identify this article as work performed under the auspices of the U.S. Department of Energy. The Los Alamos National Laboratory strongly supports academic freedom and a researcher's right to publish; as an institution, however, the Laboratory does not endorse the viewpoint of a publication or guarantee its technical correctness. 


\section{DISCLAIMER}

This report was prepared as an account of work sponsored by an agency of the United States Government. Neither the United States Government nor any agency thereof, nor any of their employees, makes any warranty, express or implied, or assumes any legal liability or responsibility for the accuracy, completeress, or usefulness of any information, apparatus, product, or process disclosed, or represents that its use would not infringe privately owned rights. Reference herein to any speciric commercial product, process, or service by trade name, trademark, manuracturer, or otherwise does not necessarily constitute or imply its endorsement, recommendation, of favoring by the United States Government or any agency thereof. The views and opinions of authors expressed herein do not neessarily state or reflect those of the United States Government or any agency thereof. 


\section{DISCLAIMER}

Portions of this document may be illegible in electronic image products. Images are produced from the best available original document. 


\title{
Effects of Thermomechanical Processing on the Resulting Mechanical Properties of 6101 Aluminum Foam
}

\author{
R. W. Margevicius, P. W. Stanek, and L. A. Jacobson \\ Los Alamos National Laboratory, Los Alamos, NM 87545
}

\begin{abstract}
Porous materials represent a tremenous weight savings for light-weight structural applications. The fabrication path can play a critical role in the resulting properties. High porosity aluminum was fabricated in a number of ways. The starting material was a cast 6101 aluminum that had a relative density of $9.8 \%$. The cast aluminum block was compressed by uniaxial, biaxial, and triaxial densification. Uniaxial compression was done at room temperature and $200^{\circ} \mathrm{C}$. Biaxial compression was achieved by unidirectional rolling at room temperature and $200^{\circ} \mathrm{C}$. Triaxial compression was done by cold isostatic pressing at $3.4,6.7$, and $34 \mathrm{MPa}(0.5,1.0$, and $5.0 \mathrm{ksi})$. Metallography and mechanical test specimens were machined from the processed bars. The mechanical properties showed that the relative yield strength depended both on relative density and processing temperature.
\end{abstract}

\section{Introduction}

It has been long realized that foaming materials is an effective means for improving some properties while not dramatically affecting others. For example, an obvious driving force for using porous materials is a reduction in density, however, thermal conductivity can remain fairly high in foamed materials (see, for example, Figure 1.3 in reference [1]).

The goal of the program being pursued at Los Alamos is the production of a 30-60\% relative density beryllium aluminum foamed material. The principal production path (and not the alternate path described in this paper) being pursued at Los Alamos is the consolidation of powder by hot isostatic pressure (HIP) where the powder is not evacuated under vacuum, but rather the trapped interparticle spacing is under pressure. This powder/pressurized gas compact, now at about 80$90 \%$ relative density, would be heated at ambient pressure to allow the argon to swell the compact by creep mechanisms. The resultant foam would be closed pore with approximately $30-60 \%$ relative density.

An alternate processing route to the production of a $30-60 \%$ relative density porous material is the densification of a less dense, e.g., $10 \%$ relative density, material. It is the purpose of the work detailed here to examine how different processing routes would affect the density achieved as well as the resulting mechanical properties. Since beryllium processing imposes daunting fabrication as well as safety issues, an aluminum was chosen first as a surrogate for the beryllium. Ultimately, beryllium and beryllium/aluminum porous structures are the goal.

\section{Materials and Methods}

\section{Cast Aluminum Foam}

A $10 \%$ relative density foam was obtained from ERG, Inc. The block was approximately $100 \times 300 \times 300 \mathrm{~mm}$ ( $4 \times 12 \times 12 \mathrm{in}$.) with a pore size of $\sim 0.8 \mathrm{~mm}$ ( 20 pores per inch). The foam is nominally an aluminum 6101 alloy $(\mathrm{Al}-0.6 \mathrm{Mg}-0.5 \mathrm{Si})$ with an as cast microstructure.

\section{Processing}

The cast aluminum foam was subject to three main processing routes, corresponding approximately to uniaxial, biaxial, and triaxial compression. Samples for densification had a minimum dimension any given direction of $25.4 \mathrm{~mm}$ ( 1 inch). Samples were compressed uniaxially in a universal testing machine at two strain rates and two temperatures. The strain rates 
tested were $0.001 / \mathrm{sec}$ and $0.1 / \mathrm{sec}$ and the temperatures tested were 25 and $200^{\circ} \mathrm{C}$. The foams compressed at $200^{\circ} \mathrm{C}$ were not processed in a furnace, but rather were put in a furnace at about $225^{\circ} \mathrm{C}$ for about 30 minutes, quickly transferred to the testing machine, and the compression test was completed in six seconds. Samples were rolled using a standard rolling mill at 25 and $200^{\circ} \mathrm{C}$. Here again, the foam was heated in a furnace at about $250^{\circ} \mathrm{C}$ for 30 minutes, removed, taken to the rolls, and rolled in about five seconds. The rolls were preheated to about $175-200^{\circ} \mathrm{C}$. Samples for CIPping were sealed in a polyethylene envelope and subjected to at $3.4,6.7$, and $34 \mathrm{MPa}(0.5$, 1.0 , and $5.0 \mathrm{ksi}$ ) isostatic pressure at room temperature. To discern the effect of densification on the resulting mechanical properties, bend tests were performed on selected foams. Samples approximately $8 \times 8 \times 40 \mathrm{~mm}$ were cut from densified foams and tested in four-point bending. While it was realize a priori that this was likely to be too small a cross section to adequately test a foam, since all the samples would have these dimensions, we felt some qualitative comparisons might be made.

\section{Results and Discussion}

\section{Compression of As-cast Foam}

The two properties of interest when looking at the foams at lower magnification are the relative density and uniformity of densification. The relative densities for all the foams processed are given in the Table below.

Densification of the as-cast foam by uniaxial compression is shown in Figure 1 . The three conditions shown are room temperature at strain rates of 0.001 and $0.1 / \mathrm{sec}$ and $200^{\circ} \mathrm{C}$ at a strain rate of $0.1 / \mathrm{sec}$. Increasing the strain rate from 0.001 to $0.1 / \mathrm{sec}$ increases the yield stress, $\sigma_{\mathrm{pl}}{ }^{*}$, from about 1.2 to $1.8 \mathrm{MPa}$. This result, however, is highly questionable. Monolithic aluminum is not strain-rate sensitive at these rates, and there is no reason to believe that the porous material is. More likely is that some imperfection (e.g., particularly large voids or weakened cell walls) existed in the foam tested at $0.001 / \mathrm{sec}$, thus lowering the $\sigma_{\mathrm{pl}} *$.

The effect of increasing the temperature from 25 to $200^{\circ} \mathrm{C}$ at constant strain rate lowers the yield stress from about 1.8 to $1.0 \mathrm{MPa}$. The yield stress is approximately $1-1.5 \mathrm{MPa}$ for the conditions tested here. A calculation of the theoretical yield stress based on the relative density is given by: [1]

$$
\frac{\sigma_{p l}^{*}}{\sigma_{y s}} \approx 0.3\left(\frac{\rho^{*}}{\rho_{s}}\right)^{1.5} .
$$

With $\sigma_{y s}$ equaling approximately $55 \mathrm{MPa}$ for $6101 \mathrm{Al}$ in an overaged condition, [2] this yields

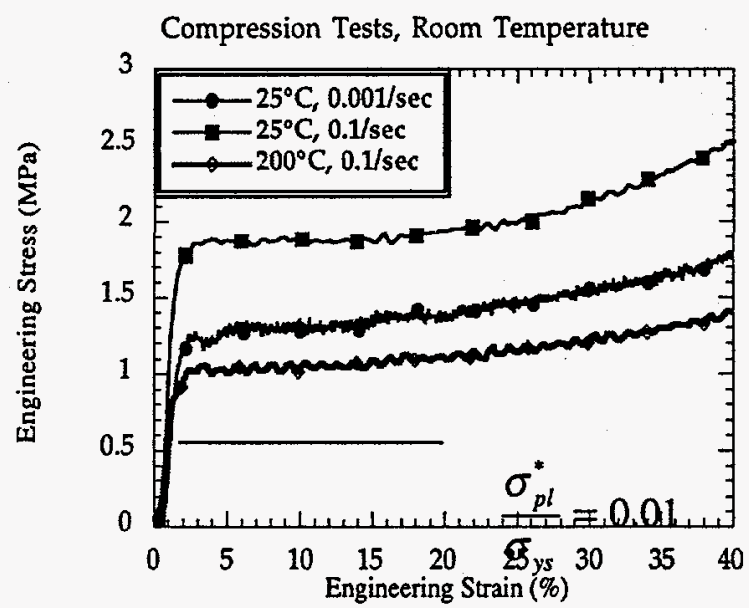

Figure 1. Compression tests of as-cast foamed aluminum.

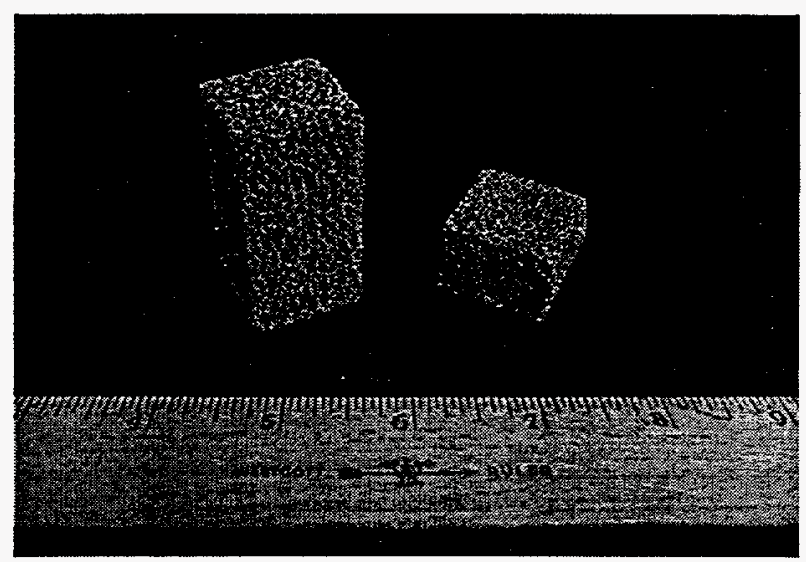

Figure 2. As-cast and compressed foams. 
$\sigma_{\mathrm{pl}} / \sigma_{\mathrm{ys}}$ of about $0.55 \mathrm{MPa}$. The yield stresses here are about two times higher. However, the exact condition of the as-cast foam has not been determined and is the subject of continuing research. An overaged condition is assumed; however, something between peak aged and overaged is certainly possible. The densification strain (not shown in Figure 1) was approximately $50-60 \%$.

Table. Resulting relative densities from the various processing paths.

\begin{tabular}{cccc}
\hline Process & Conditions & $\begin{array}{c}\text { Process } \\
\text { Temperature }\left({ }^{\circ} \mathrm{C}\right)\end{array}$ & $\begin{array}{c}\text { Relative Density } \\
\text { (percent) }\end{array}$ \\
\hline \hline $\begin{array}{c}\text { Uniaxial } \\
\text { Compression }\end{array}$ & $0.001 / \mathrm{sec}$ & 25 & 23 \\
& $0.1 / \mathrm{sec}$ & 25 & 27 \\
& $0.1 / \mathrm{sec}$ & 200 & 29 \\
\hline Rolling & 30\% reduction, one pass & 25 & 11 \\
& 30\% reduction, six passes & 25 & 11 \\
& $65 \%$ reduction, two passes & 25 & 18 \\
& $65 \%$ reduction, six passes & 25 & 19 \\
& $65 \%$ reduction, one pass & 200 & 23 \\
\hline CIP & $3.4 \mathrm{MPa}$ & 25 & 20 \\
& $6.7 \mathrm{MPa}$ & 25 & 31 \\
& $34 \mathrm{MPa}$ & 25 & 50 \\
\hline
\end{tabular}

Occasionally compression of the foams from $50.8 \mathrm{~mm}$ to $18 \mathrm{~mm}$ caused a slight buckling, Figure 2. Although all three foams were compressed the same amount, slight differences in the relative densities were measured. We have not determined whether this is due to a sampling error or whether the effect is genuine. The desification of the foams was rather uniform, Figure 3. Although slight differences in densities were measured, this difference is likely due to sampling error rather than an intrinsic difference.

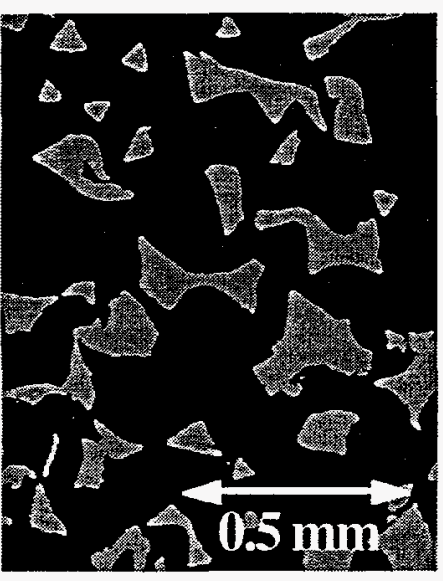

$25^{\circ} \mathrm{C} 0.001 / \mathrm{sec}$ $23 \%$ density

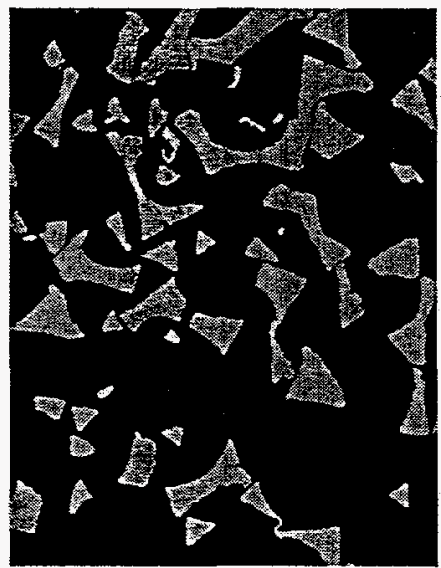

$25^{\circ} \mathrm{C} 0.1 / \mathrm{sec}$

$27 \%$ density

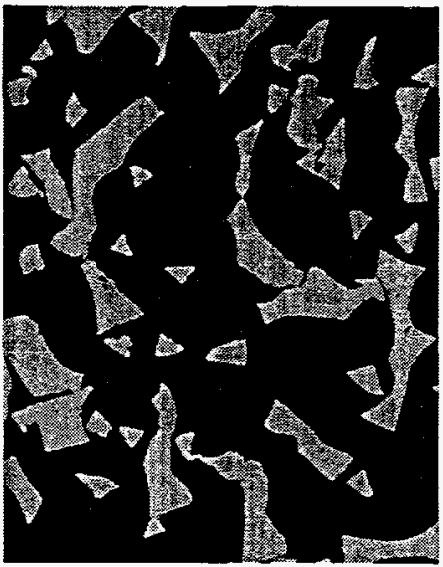

$200^{\circ} \mathrm{C} 0.1 / \mathrm{sec}$ $29 \%$ density

Figure 3. Densification microstructures of the uniaxially compressed foams. 


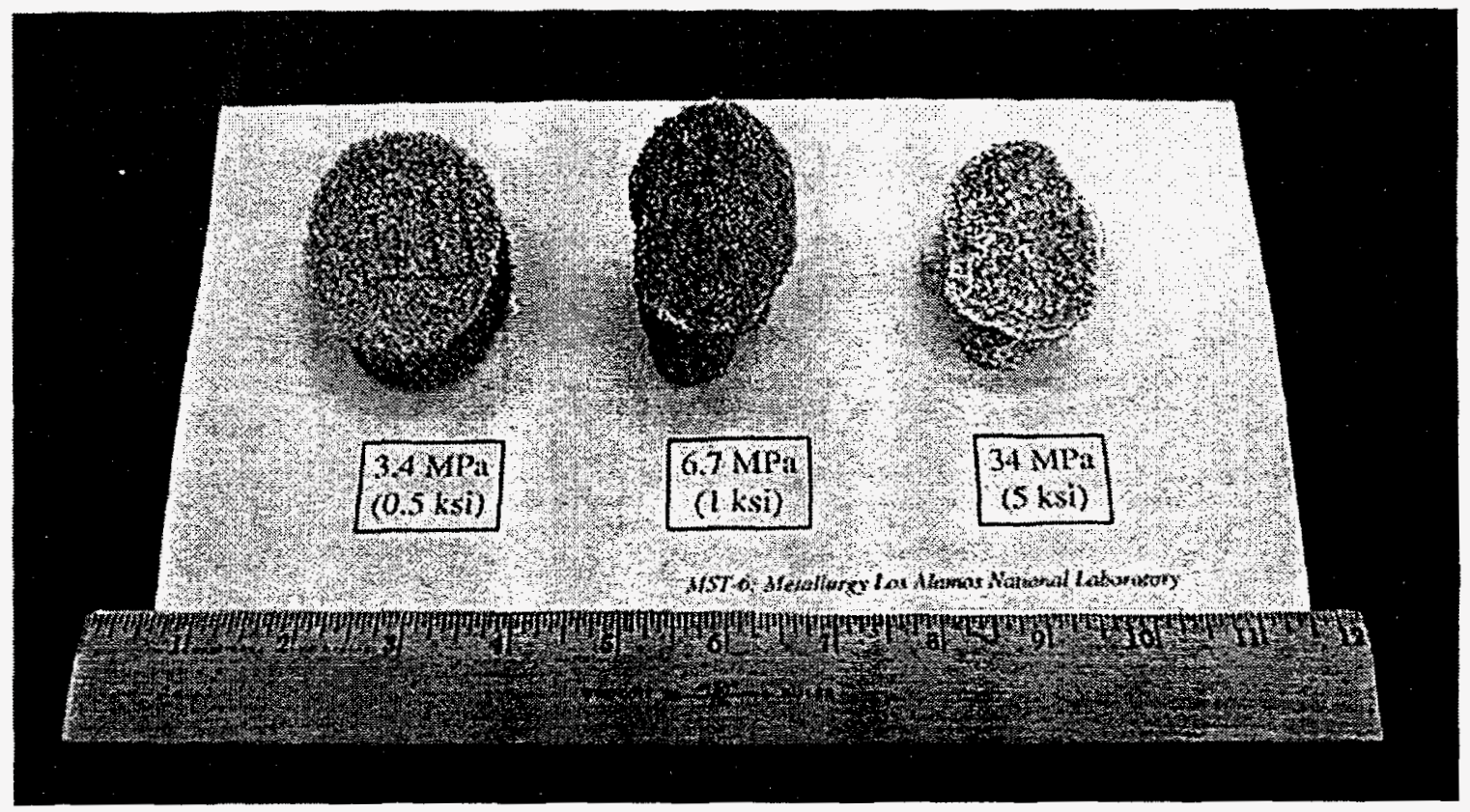

Figure 4. Anisotropic compaction of CIPped foams at 3.4, 6.7, and $34 \mathrm{MPa}$.

\section{Cold Isostatic Pressing (CIPping)}

Cold isostatic pressing of the foam did not isotropically compact the foam, Figure 4 . Independent of CIP pressure, the resulting shape of the once cylindrical piece was an elliptical cylinder. This may indicate some natural anisotropy present in the foam. To date, we have not kept track of the original thin dimension of the cast plate, but samples were taken such that the original cylindrical axes were parallel to one long direction of the cast block (viz., the short direction of the cast block is parallel to the diameter of the cylinder).

CIPping did compact the foams, Figure 5. The lowest pressure we were able to produce, 3.4 $\mathrm{MPa}$, compacted the originally $9.8 \%$ relative density foams to $20 \%$. Increases in pressure produced correspondingly higher densities, Figures 5 and 6 . Relative density increases dramatically at lower pressures and begins to saturate at the highest pressure, $34 \mathrm{MPa}$. This would be expected from the way in which foams densify; that is, at low densities, the large volume fraction of porosity does not interfere with the cell walls that are coming closer to each other. Once cell walls begin to impinge, correspondingly higher pressures are required to continue densification of the foam.

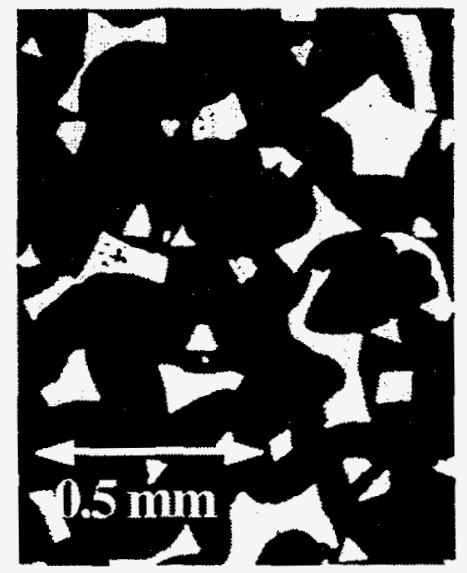

3.4 Mpa, $20 \%$ density

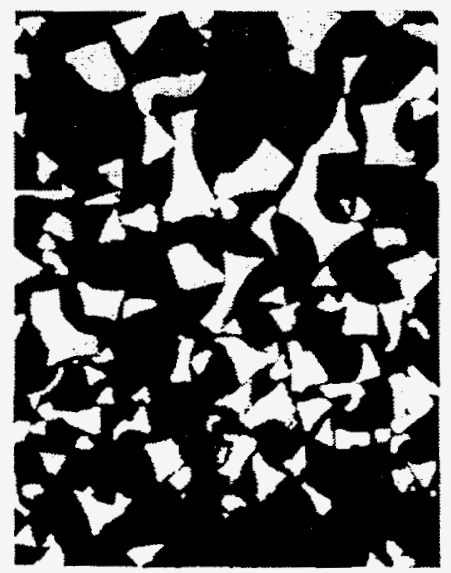

6.7 $\mathrm{MPa}, 31 \%$ density

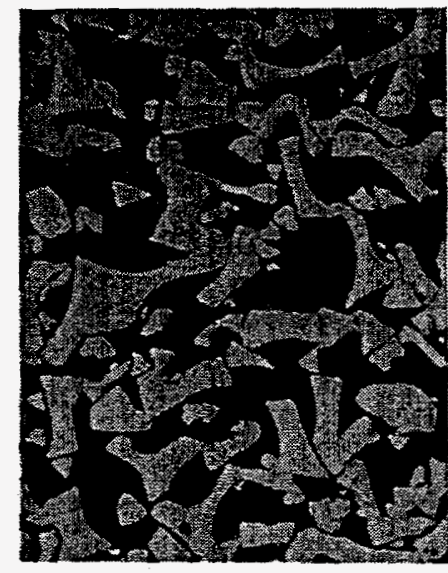

$34 \mathrm{MPa}, 50 \%$ density

Figure 5. Compaction of CIPped foams 


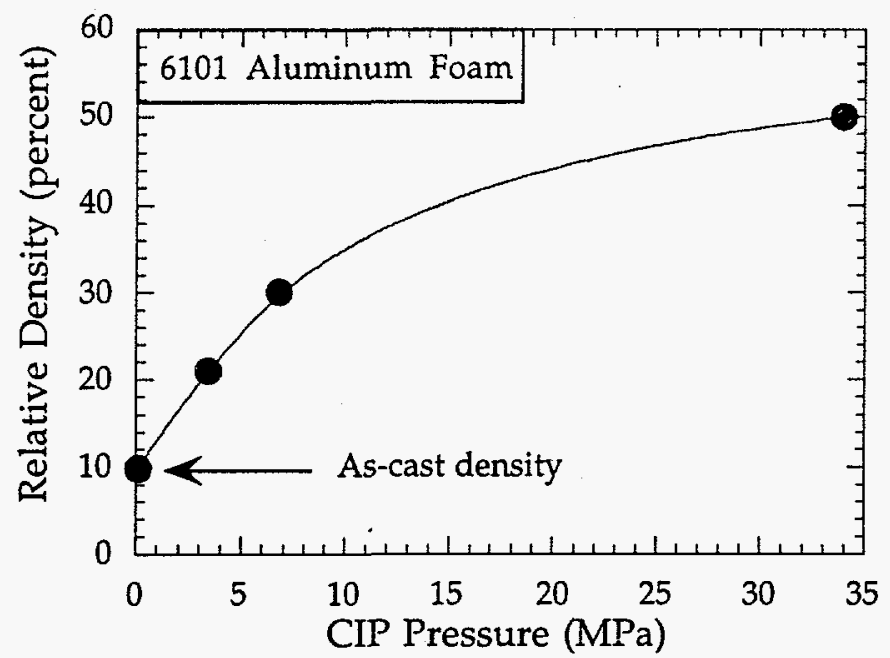

Figure 6. Density vs. CIP pressure for as-cast aluminum foam

\section{Rolling}

The densification of the rolled foamed occurred qualitatively in the same fashion as the CIPped samples, that is, at $30 \%$ reduction it increased from $9.8 \%$ to $11 \%$ dense, while at $65 \%$ reduction, the density increased to about $20 \%$, Table. One concern was that the rolling process would densify the surfaces of the foams more and the inner part less. This did not apparently happen, Figure 7. The black strips on the top and bottoms of the left two micrographs represent the top and bottoms of the rolled foams. No higher density at the surfaces is readily apparent. Qualitatively, there is no difference in the microstructure between the samples rolled at $25^{\circ} \mathrm{C}$ and $200^{\circ} \mathrm{C}$, Figure 7.

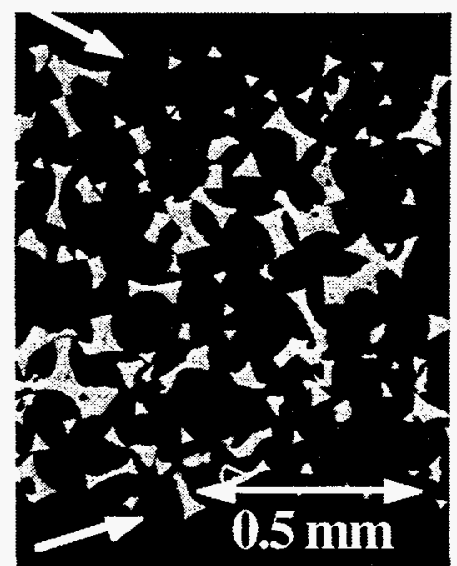

$65 \%$ reduction, 13 passes, $25^{\circ} \mathrm{C}$ $18 \%$ density

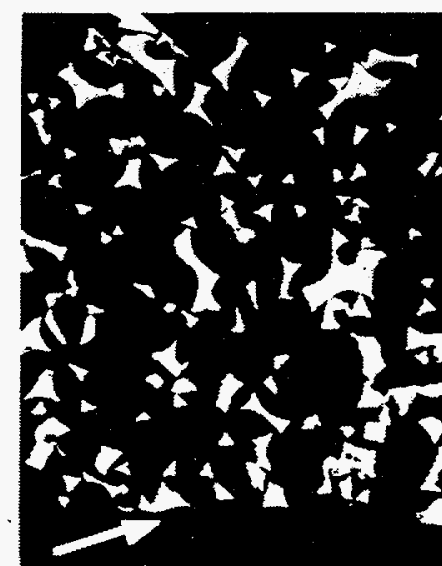

$65 \%$ reduction, 2 passes, $25^{\circ} \mathrm{C}$ $19 \%$ density

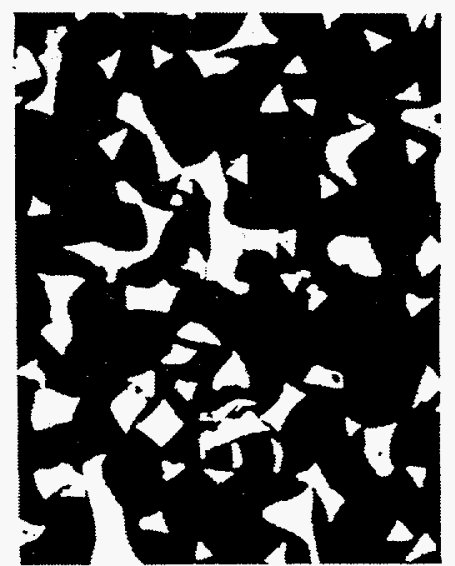

$65 \%$ reduction, 1 pass, $200^{\circ} \mathrm{C}$ $23 \%$ density

Figure 7. Densification of rolled foams (arrows indicate the top and bottom rolling surfaces).

\section{Bend Tests}

Bend samples compressed at room temperature, (i.e., rolled at $25^{\circ} \mathrm{C}$ in two and 13 passes and CIPped at $6.7 \mathrm{MPa}$ ) with approximately the same density all had very similar stress displacement traces, Figure 8. The sample that had been machined from the bar rolled at $200^{\circ} \mathrm{C}$ had an 
appreciably lower curve, while that taken from the CIP $34 \mathrm{MPa}$ material had a much higher curve. The CIP $34 \mathrm{MPa}$ sample can be understood in terms of its dramatically higher $50 \%$ relative density. The rolled $200^{\circ} \mathrm{C}$ curve was an interesting observation; while the relative density was similar to the room temperature samples, it is clear that the higher temperature processing did allow for some recovery to take place.

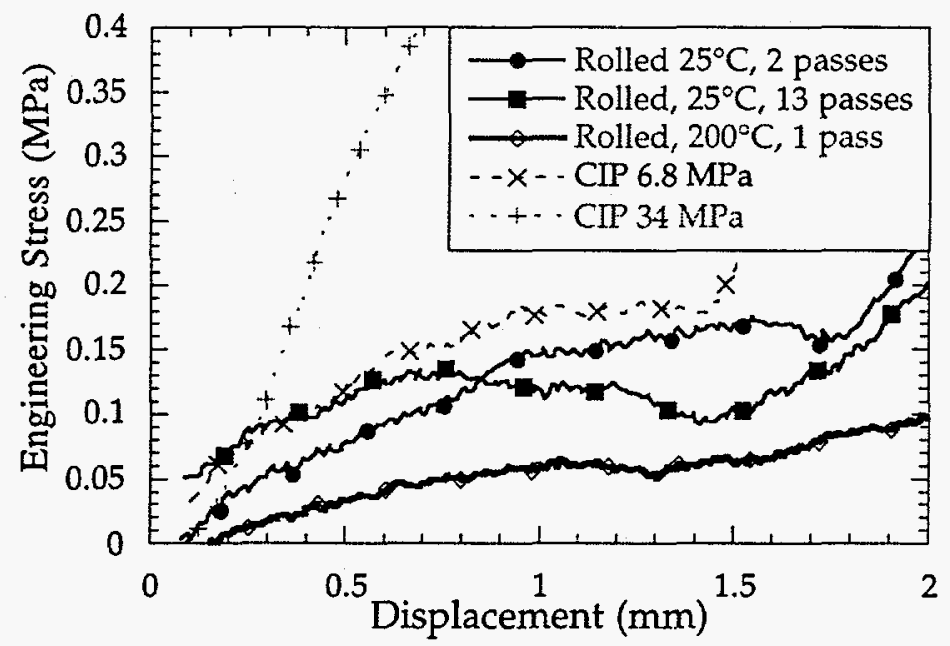

Figure 8. Room temperature bend tests of foams compacted by various methods.

\section{Acknowledgments}

We would like to acknowledge DARPA for financial support. We would also like to thank D. Sandoval and D. Rodella for helping with the mechanical testing and J. Montoya and A. Kelly for the help with metallography.

\section{References}

1. Cellular Solids, Structure and Properties, second edition, L. J. Gibson and M. F. Ashby, Cambridge University Press, Cambridge, UK, 1997.

2. ASM Handbook, vol. 2, ASM International, 104-5, 1990. 